\title{
Rotary Files in Pediatric Dentistry: From Then Till Now
}

\author{
Pragadeesh A Pitchiah ${ }^{1}$, Prathima G Shivashankarappa ${ }^{2}$
}

\begin{abstract}
The introduction of adult NiTi rotary file system for children was a revolution in the field of pediatric endodontics. With the use of these files, cost-effective, consistent obturations were made possible in shorter instrumentation time. The various restraints of adult rotary files such as file length and taper created the need for newer rotary file system. These voids were fulfilled with the advent of exclusive pediatric rotary fileKedo-S file system. In this article, we have discussed how the innovative pediatric rotary files have made its mark overpowering the limitations of the existing adult rotary file system in children.
\end{abstract}

Keywords: Kedo-S, Primary teeth, Pulpectomy, Root canal preparation, Rotary files.

Journal of Scientific Dentistry (2020): 10.5005/jp-journals-10083-0926

\section{INTRODUCTION}

The principal goal in pediatric dentistry is to retain the primary teeth in the oral cavity until its physiological exfoliation to preserve arch integrity. ${ }^{1}$ One of the treatment options for pulpally affected primary molars is pulpectomy, which has several advantages over extraction. ${ }^{2}$ The complex root canal system of primary teeth plays a main part in the outcome of the treatment, which will affect the success of root canal therapy. ${ }^{3}$ Instrumentation of root canals is carried out with the primary objective to remove the infection, ${ }^{4}$ and this greatly determines the success of pulpectomy. ${ }^{5}$

Biomechanical preparation with rotary files in primary teeth has gained popularity when the first case was reported by Barr et al. using ProFile 0.04 taper permanent rotary instruments. However, it has disadvantages of over-instrumentation in primary tooth roots because of its relatively thin canal walls and difficulties in fully instrumenting flat, oval, curved, and irregularly shaped canals. ${ }^{6}$ In addition, pediatric patients have limited mouth opening and the longer length of adult rotary files makes it difficult for use. ${ }^{7}$ Various rotary instruments that have been introduced for root canal shaping in permanent teeth offer several advantages over the manual instrumentation in primary root canal preparation (Bergmans et al. 2001, Kleier and Averbach 2006, Cheung and Liu 2009). In this article, we have discussed the features, advantages, and disadvantages of various generations of adult rotary files used in children and various exclusive pediatric endodontic files.

The first evidence of rotary instrumentation was the use of fine needles having a rectangular cross section and attached to the dental handpiece by Oltramare (1892). With the introduction of NiTi hand instruments by 1988, various rotary NiTi instruments were made commercially available for the past few decades. ${ }^{8}$ These NiTi rotary files play a vital role in pulpectomy procedure. Depending on the taper, blade, shaft, and groove of the rotary files, they have been classified into various generations of adult NiTi rotary files.

\section{First-generation NiTi Files}

NiTi ProFile files have noncutting tip, fixed taper ( $2 \%, 4 \%$, and $6 \%$ ), negative rake angle, and passive cutting blades. ${ }^{9}$ These files were used for the first time in primary teeth by Barr et al., which resulted in less chairside instrumentation time, and obturation was found to be uniform and consistent. ${ }^{10,11}$ FlexMaster files have round passive tips,
${ }^{1,2}$ Department of Pediatric and Preventive Dentistry, Indira Gandhi Institute of Dental Sciences, Sri Balaji Vidyapeeth, Puducherry, India

Corresponding Author: Pragadeesh A Pitchiah, Department of Pediatric and Preventive Dentistry, Indira Gandhi Institute of Dental Sciences, Sri Balaji Vidyapeeth, Puducherry, India, Phone: +91 9384156656, e-mail: pragadeesh2812@gmail.com

How to cite this article: Pitchiah PA, Shivashankarappa PG. Rotary Files in Pediatric Dentistry: From Then Till Now. J Sci Dent 2020;10(2):55-57.

Source of support: Nil

Conflict of interest: None

convex triangular shape with sharp cutting edges, and increased dentin cutting efficiency. ${ }^{9}$ These files were faster than manual $\mathrm{K}$ files ${ }^{12}$ and resulted in better radiographic findings ${ }^{13}$ in pulpectomy procedure. Hero 642 files have an inactive tip, a constant taper, and a triple helix geometry, ${ }^{9}$ which help in less dentin removal than manual instrumentation. ${ }^{14}$ However, these first-generation files require several files to complete the root canal preparation, which is a major disadvantage. ${ }^{15}$

\section{Second-generation NiTi Files}

These second-generation files have modified active cutting edges and require fewer instruments for the completion of the root canal preparation compared to first-generation files. ${ }^{15}$ Hero Shaper files have the features of inactive tip, constant taper, and positive rake angle, which are useful in crown-down technique. ${ }^{9}$ They also have enhanced shaping ability and cleaning efficacy with diminished preparation time and instrument distortion in primary molars than manual $\mathrm{K}$ files. However, there is an increased chance of lateral perforation when used in primary tooth, especially in curved roots. ${ }^{16}$ K3 rotary files with safe-ended tip have an added advantage of apical debris extrusion compared to Hero Shaper files. ${ }^{17}$ ProTaper files have multiple tapers along with modified guiding tip, ${ }^{9}$ whose cleaning efficacy is similar to that of manual instrumentation with less chairside time ${ }^{18}$ and success rate of $96 \% .{ }^{19}$ Mtwo files with $\mathrm{S}$-shaped cross section and positive rake angle ${ }^{9}$ have shown similar cleaning efficacy in primary root canal preparation. ${ }^{20}$ However, these instruments have a disadvantage of canal transportation and instrumentation breakage. ${ }^{15}$ 


\section{Third-generation NiTi Files}

These generation files, utilizing M-Wire technology, have reduced cyclic fatigue and less chance of instrument breakage. ${ }^{15}$ WaveOne rotary files are single file system, which has a modified tip with variable taper useful in reciprocating motion. ${ }^{9}$ This reciprocating system (WaveOne) showed better cleaning efficiency, particularly in the coronal and middle one-third of root canals. ${ }^{21}$

\section{Fourth-generation NiTi Files}

Reciproc fourth-generation files differ from third-generation files by having a S-shaped cross section to be used in reciprocating motion ${ }^{9}$ and achieve greater cleaning efficiency in significantly shorter duration of time when compared with Mtwo and K files in primary teeth. ${ }^{22,23}$

\section{Fifth-generation NiTi Files}

These generation files such as ProTaper Next files have improved flexibility with maximum debris removal, which is considered as a hybrid technique. ${ }^{15}$ These files are asymmetric with modified tip, variable taper utilizing M-Wire technology. ${ }^{9}$ They are better than the Mtwo, Revo-S, and hand files in relation to apical extrusion of debris during canal preparation of primary molar teeth. ${ }^{24}$

The above generations of files are frequently used for permanent teeth. The major limitations while using them in primary teeth are the thinner curved roots with ribbon-shaped morphology increasing the chance of lateral perforation. Apart from this, the longer file length makes it difficult to work in pediatric patient. ${ }^{7}$ This creates the requirement of pediatric endodontic rotary files.

\section{Pro-AF Baby Gold Files}

Pro AF Baby Gold file, specially designed pediatric rotary file with NiTi CM-Wire technology, is flexible and has constant taper of $4 \%$ and $6 \%$. They comprise of five files of $17 \mathrm{~mm}$ long and mostly require only two files for preparation. ${ }^{25}$

\section{Prime Pedo Files}

These files are memory controlled having a triangular cross section and are heat treated. They have improved cleaning efficacy and produce better obturation compared to manual instrumentation. ${ }^{6}$

\section{DXL-Pro-TM Files}

DXL-Pro-TM files have a guiding noncutting tip and convex triangular cross section with controlled memory. They have better cleaning efficiency and produce better obturation than Prime Pedo files. 6

\section{Kedo-S Pediatric Rotary File System}

Kedo-S rotary files are exclusively developed pediatric rotary files with modified length, taper, and tip size to perform pulpectomy in an effective and convenient way. ${ }^{7}$ There are four generations of Kedo-S rotary file system available.

\section{Kedo-S Rotary Files-First-Generation Kedo-S Files}

Kedo-S rotary file is a single NiTi rotary file system consisting of D1, E1, and U1 files, wherein U1 files are for upper and lower anterior primary teeth, D1 for mesiobuccal and mesiolingual canals, and E1 for distal and palatal canals of the primary molar teeth. They have a working length of $12 \mathrm{~mm}$ with a total length of $16 \mathrm{~mm}$. The uniqueness of these files is the presence of variable taper $(4 \%-8 \%)$ with varying tip diameter. ${ }^{7}$ The tapering of the instrument is according to the diameter of the primary root canal to enable effective canal preparation and to avoid over-instrumentation. ${ }^{7}$ With the use of Kedo-S instrument in curved canals, the original anatomy of primary root canal can be maintained, which is mainly because of the file design and flexibility. This enables it to closely adapt to the irregular and tortuous canals of primary teeth. ${ }^{9}$

The Kedo-S rotary files have instrumentation time of 2-3 minutes approximately. ${ }^{7}$ This greatly reduces the operator and patient's fatigue, thereby increasing the quality of the treatment. ${ }^{7}$ These files render better quality of obturation while comparing with reciprocating and manual instrumentation. ${ }^{26}$ Yet, Kedo-S rotary files have some disadvantages that include the high cost of the constant torque handpiece and the files itself. For using Kedo-S files, it requires appropriate training for better results. ${ }^{7}$

\section{Kedo-SG Rotary Files-Second-Generation Kedo-S Files}

Kedo-SG rotary files are heat-treated NiTi rotary files utilizing the M-Wire technology. These files result in better obturation quality due to its efficient preparation of primary root canals. ${ }^{27}$

\section{Kedo-SG Blue-Third-Generation Kedo-S File System}

The next generation is the Kedo-SG Blue consisting of three files D1, E1, and U1, which have greater cyclic fatigue resistance with its titanium oxide coating. These files are super flexible and have $75 \%$ of greater resistance to cyclic fatigue than its earlier generation. ${ }^{25}$

\section{Kedo-S Square-Fourth-Generation Kedo-S File System}

The newer generation Kedo-S Square consists of P1 file for molars and A1 file for anteriors. They also have variably variable cross section; that is, the apical $5 \mathrm{~mm}$ has triangular cross section with three-point contact to root canal, whereas the coronal $7 \mathrm{~mm}$ has teardrop cross section with two-point contact. This enables reduced apical dentin removal and less aggressive preparation.

\section{Advantages of Kedo-S Square}

- Superior flexibility,

- Less dentin removal, and

- Increased resistance to cyclic fatigue due to its $\mathrm{TiO}_{2}$ coating.

\section{Conclusion}

Considering the advantages of Kedo-S Square files, with proper training of operator, comparatively efficient instrumentation rendering better obturation quality can be achieved in shorter instrumentation time.

\section{References}

1. Ranly DM, Garcia-Godoy F. Current and potential pulp therapies for primary and young permanent teeth. J Dent 2000;28(3):153-161. DOI: 10.1016/S0300-5712(99)00065-2.

2. Ruddle CJ.Cleaning and shaping the root canal system. In: Cohen S, Burns RC. Pathways of the pulp. 8th ed., St. Louis: Mosby; Inc; 2002. p. 231-292.

3. Ellana Jermiah J, Rao A, Srikant N, Rao A, Suprabha BS. Comparative evaluation of three obturating techniques in primary molars: an in vivo study. J Clin Pediat Dent 2019;43(6):372-375. DOI: 10.17796/10534625-43.6.2.

4. Moghaddam KN, Mehran M, Zadeh HF. Root canal cleaning efficacy of rotary and hand files instrumentation in primary molars. Iran Endod J 2009;4:53-71. 
5. Haapasalo M, Endal U, Zandi H, Coil JM. Eradication of endodontic infection by instrumentation and irrigation solutions. Endod Topics 2005;10(1):77-102. DOI: 10.1111/j.1601-1546.2005.00135.x.

6. Katge F, Ghadge S, Poojari M, Jain K, Patil D. Comparative evaluation of cleaning efficacy of Prime Pedo ${ }^{T M}$ and DXL-Pro ${ }^{T M}$ Pedo rotary files with conventional $\mathrm{H}$ files in root canals of primary teeth: an in vitro study. J Clin Diagnos Res 2019;13(7).

7. Jeevanandan G. Kedo $S$ paediatric rotary files for root canal preparation in primary teeth-case report. J Clin Diagn Res 2017;11(3):ZR03-ZR05. DOI: 10.7860/JCDR/2017/25856.9508.

8. Çapar ID, Arslan H. A review of instrumentation kinematics of enginedriven nickel-titanium instruments. Int Endod J 2016;49(2):119-135. DOI: 10.1111/iej.12432.

9. Krishan S, Aggarwal A, Singh K. Endodontic rotary systems-a review. J Adv Med Dent Sci Res 2016;4(2):84.

10. Barr ES, Kleier DJ, Barr NV. Use of nickel-titanium rotary files for root canal preparation in primary teeth. Pediatr Dent 2000;22(1):77-78.

11. Shashikiran ND. In vitro comparison of NiTi rotary instruments and stainless steel hand instruments in root canal preparation of primary and permanent molars. J Indian Soc Pedod Prev Dent 2006;24(4): 186-191. DOI: 10.4103/0970-4388.28075.

12. Bahrololoomi Z, Tabrizizadeh M, Salmani L. In vitro comparison of instrumentation time and cleaning capacity between rotary and manual preparation techniques in primary anterior teeth. J Dent Tehran Univers Med Sci 2007. 59-62.

13. Abbas M, Navid R, Masoumeh E. Radiographic assessment and chair time of rotary instruments in the pulpectomy of primary second molar teeth: a randomized controlled clinical trial. J Dent Res Clin Dent Prospect 2014;8:84-89.

14. Kummer TR, Calvo MC, Cordeiro MM, de Sousa Vieira R, de Carvalho Rocha MJ. Ex vivo study of manual and rotary instrumentation techniques in human primary teeth. Oral Surg, Oral Med, Oral Pathol, Oral Radiol Endod 2008;105(4):e84-e92. DOI: 10.1016/ j.tripleo.2007.12.008.

15. Ruddle CJ, Machtou P, West JD. The shaping movement 5 th generation technology. Dent Today 2013;32(4):94.

16. Musale PK, Mujawar SA. Evaluation of the efficacy of rotary versus hand files in root canal preparation of primary teeth in vitro using CBCT. Eur Arch Paediatr Dent 2014;15(2):113-120. DOI: 10.1007/s40368013-0072-1.
17. Rosa FM, Modesto A, Faraco-Junior IM. Manual and rotary instrumentation techniques for root canal preparation in primary molars. Dentistry 3000 2014;2(1). DOI: 10.5195/D3000.2014.19.

18. Kuo Cl, Wang YL, Chang HH, Huang GF, Lin CP, Guo MK. Application of $\mathrm{Ni}-\mathrm{Ti}$ rotary files for pulpectomy in primary molars. J Dent Sci 2006;:1:10-15.

19. Pinheiro SL, Araujo G, Bincelli I, Cunha R, Bueno C. Evaluation of cleaning capacity and instrumentation time of manual, hybrid and rotary instrumentation techniques in primary molars. Int Endod J 2012;45(4):379-385. DOI: 10.1111/j.1365-2591.2011.01987.x.

20. Reza AM, Laya S, Afshin N. Comparison of the cleaning capacity of MTWO Pro taper and rotary systems and manual instruments in primary teeth. Dent Res J 2012;9(2):146-151. DOI: 10.4103/17353327.95227.

21. Katge F, Patil D, Poojari M, Pimpale J, Shitoot A, Rusawat B. Comparison of instrumentation time and cleaning efficacy of manual instrumentation, rotary systems and reciprocating systems in primary teeth: an vitro study. J Indian Soc Pedod Prev Dent 2014;32(4):311-316. DOI: $10.4103 / 0970-4388.140957$.

22. Ramazani N, Mohammadi A, Amirabadi F, Ramazani M, Ehsani F. In vitro investigation of the cleaning efficacy, shaping ability, preparation time and file deformation of continuous rotary, reciprocating rotary and manual instrumentations in primary molars. J Dent Res Dent Clin Dent Prospects 2016;10(1):49. DOI: 10.15171/ joddd.2016.008.

23. Yuvaraj S, Antony SD, Continuous V/S Reciprocating File Motion-A Review.

24. Topçuoğlu G, Topçuoğlu HS, Akpek F. Evaluation of apically extruded debris during root canal preparation in primary molar teeth using three different rotary systems and hand files. Int J Paediatr Dent 2016;26(5):357-363. DOI: 10.1111/ipd.12208.

25. Thakkar TK. Advances in rotary endodontics in pediatric dentistry. EC Dent Sci 2019;18:1320-1330.

26. Lakshimi Lakshmanan, Geo Mani, Ganesh Jeevanandan, Vignesh R. January 2020 Brazilian Dental Science 23(1). DOI: 10.14295/bds.2020. v23i1.1822.

27. Garg S, Kedo-SG pediatric rotary files: A boon for rotary endodontics in primary teeth. Garg S. Kedo-SG pediatric rotary files: A boon for rotary endodontics in primary teeth. 